\title{
WRF-urban canopy model evaluation for the assessment of heat island and thermal comfort over an urban airshed in India under varying land use/land cover conditions
}

Shweta Bhati and Manju Mohan*

\begin{abstract}
Urban heat island effect has been assessed using weather research and forecasting model (WRF v3.5) focusing on air temperature and surface skin temperature in the sub-tropical urban Indian megacity of Delhi. Impact of urbanizationrelated changes in land use/land cover (LULC) on model outputs has been analyzed. Four simulations have been carried out with different types of LULC data viz. (1) USGS, (2) MODIS, (3) user-modified USGS and (4) user-modified land use data coupled with urban canopy model (UCM) for incorporation of canopy features. Heat island intensities have been estimated based on these simulations and subsequently compared with those derived from in situ and satellite observations. There is a significant improvement in model performance with modification of LULC and inclusion of UCM. Overall, RMSEs for near surface temperature improved from 6.3 to $3.9^{\circ} \mathrm{C}$ and index of agreement for mean urban heat island intensities (UHI) improved from 0.4 to 0.7 with modified land use coupled with UCM. In general, model is able to capture the magnitude of $\mathrm{UHI}$ as well as high $\mathrm{UHI}$ zones well. A simple method of bias correction in model has been applied to improve model results for further application. The study highlights the importance of appropriate and updated the representation of land use-land cover and urban canopies for improving predictive capabilities of the mesoscale models. Urban heat island has been known to have effect on human thermal comfort. In the present study, Heat Index, a commonly used indicator of thermal comfort, is assessed spatially using WRF-UCM derived results. Urban areas were found to have higher Heat Index than non-urban areas by a difference of about $1.5-2^{\circ} \mathrm{C}$. Further, it was found that urban canopy effect leads to rise in thermal discomfort by increasing Heat Index. There is an increase in Heat Index of about $2.0-2.5^{\circ} \mathrm{C}$ at dense built-up stations. Decrease in thermal comfort causes a significant impact on energy demand. Hence, analysis of urban heat island effect vis-a-vis thermal comfort provides useful information with regard to impact on human comfort and welfare.
\end{abstract}

Keywords: Urban heat island, WRF model, UHI hotspots, Model evaluation, Land use-land cover, Urban canopy model, Thermal comfort, Heat Index

\section{Introduction}

Land surface processes impact meteorology on local as well as climate time scales. Land cover and land use are essential parameters in land surface processes. Fluxes of heat, momentum, and moisture are parameterized in numerical weather predictions models through coupled

*Correspondence: mmohan66@gmail.com; mmanju@cas.iitd.ac.in Centre for Atmospheric Sciences, Indian Institute of Technology Delhi, Hauz Khas, New Delhi 110016, India land surface models as functions of surface albedo, surface moisture availability, surface emissivity, surface roughness, and surface thermal inertia. Land use and cover determine these inputs to be used by land surface models which compute land-atmosphere fluxes. Hence, land use data are an important component of a meteorological model. The weather research forecasting model (WRF) is a widely used mesoscale model which finds application in both meteorology and air quality analysis. The default geographic datasets of WRF model are based 
on the old satellite datasets. The megacity Delhi has experienced rapid urbanization and population growth in the last decade. Mohan et al. (2011) observed that built-up area of Delhi witnessed an overall increment of 16.86\% during 1997-2008 which mainly came from agriculture land, waste land, scrub land, sandy areas and water bodies. Consequently, there is a substantial mismatch between model inputs for land use data with those from the actual land use, especially for Delhi region. An updated land use data, thus, provides a scope in improvement of model performance.

Jiang et al. (2014) simulated land cover changes under pre-designed scenarios and then analyzed the effects of land cover conversion on energy flux in the semiarid grassland area of China using WRF model. It was concluded that there would be significant surface energy flux changes due to rapid economic growth scenario. Cheng et al. (2013) used three land use datasets viz USGS, MODIS and SPOT satellite imagery to analyze WRF performance for Taiwan region. Ravindranath et al. (2010) compared WRF performance with USGS and AWiFSderived land cover dataset for India and deduced that land cover changes can alter not just micrometeorological features but also large-scale circulation patterns. López-Espinoza et al. (2012) used 2009 land use map of the Instituto Nacional de Estadística y Geografía, Mexico (INEGI) as input land use in WRF model for three cities in Mexico. The model results for temperature were compared against 1992 GLCC data-based land use and an average increase $1.33{ }^{\circ} \mathrm{C}$ was observed in daily maximum temperature with new land cover data.

The present study is aimed at analyzing impact of change in input land cover on model-simulated parameters such as near surface temperature and surface skin temperature. The impact of incorporation of urban canopy features along with modifications in LULC has also been analyzed. Three different types of land use data have been applied to the model viz. USGS land use data, MODIS-based land use data and user-modified USGS land use data. A coupled simulation with modified land use data and urban canopy model has also been carried out. Model performance has been evaluated for temperature and surface skin temperature based on statistical parameters. Further urban heat island intensities (UHI) have been computed for all four simulation cases for varying land use and compared with the UHI estimations based on observations and the impacts on model performance analyzed.

\section{Description of land use datasets USGS land use data (USGS)}

There are two land use datasets that are available with WRF model in its geographical input database. The USGS land use database was generated by the United States
Geological Survey's (USGS) National Center for Earth Resources Observation and Science (EROS), the University of Nebraska-Lincoln (UNL) and the Joint Research Centre of the European Commission. This is a global land cover characteristics database with a resolution of $1 \mathrm{~km}$. The data set is derived from 1-km Advanced Very High Resolution Radiometer (AVHRR) data spanning a 12-month period (April 1992-March 1993) (USGS GLCC 2015). The data are divided into different levels according to the land use details. There are 24 categories of different land use in level 2 of this dataset which have been classified based on Anderson et al. (1976). The 24 category land use data are the default land use dataset in WRF model.

\section{MODIS-based land use data (MODIS)}

The MODIS land cover type product is derived from observations spanning a year input of Terra and Aqua data. The land cover scheme used in WRF identifies 20 land cover classes defined by the International Geosphere Biosphere Programme (IGBP). The dataset that comes with WRF is based on year 2001 (Ran et al. 2010). It has a resolution of $1 \mathrm{~km}$ and can be used only with Noah land surface model. Recently, with WRF version 3.6 release, MODIS land use dataset is also available at resolution of $15 \mathrm{~s}(\sim 500 \mathrm{~m})$.

\section{Modified USGS land use data (Modified)}

The major differences, especially in terms of urban land cover, have been observed in USGS data and present LULC. Though MODIS land use data are comparatively more recent than USGS, it has been designed to couple with only Noah land surface model (LSM). Thus, it has limitations in terms of compatibility with various land surface model schemes in WRF model, while USGS land use data can be used with all LSM schemes. Hence, in the present study, the USGS data set has been modified according to the recent or actual land use scenario. The source of the present land use data includes surveys in field study during the field campaign carried out for urban heat island analysis in the study domain in May 2008 (Mohan et al. 2012) and March 2010 (Mohan et al. 2013), classified satellite data (Mohan et al. 2011) and satellite data of the commercial mapping and GIS program, Google Earth.

\section{Modified land use data coupled with urban canopy model (UCM)}

This is essentially simulation with modified USGS coupled with urban canopy model. A single-layer urban canopy model (UCM) developed by Kusaka and Kimura (2004) has been coupled with WRF for better representation of surface energy balance in urban areas. The UCM consists of two-dimensional, symmetrical street canyons with simplified geometry of the buildings. The model 
estimates the surface temperature of roof, wall and road surfaces as well as the fluxes from these surfaces (Tewari et al. 2004). UCM requires inputs of urban canopy features such as building height, width and street width and thermal properties of building material.

\section{Model description}

The weather research and forecasting model is developed for mesoscale modeling. Its development is led by NCAR, NOAA/ESRL, and NOAA/NCEP/EMC with partnerships and collaborations with universities and other government agencies in the US and overseas. The advanced research WRF (ARW) dynamical core has an equation set which is fully compressible, Eulerian and non-hydrostatic with a run-time hydrostatic option. It is conservative for scalar variables. The model uses terrain-following, hydrostatic-pressure vertical coordinate with the top of the model being a constant pressure surface. The horizontal grid is the Arakawa-C grid. The time integration scheme in the model uses the third-order Runge-Kutta scheme, and the spatial discretization employs 2nd- to 6th-order schemes. The model supports both idealized and realdata applications with various lateral boundary condition options. The model also supports one-way, two-way, and moving nest options (UCAR 2014).

\section{Domain and simulation period}

The simulation design consists of three domains (Fig. 1). The parent domain (D1) covers the Indian subcontinent with a spatial resolution of $18 \mathrm{~km}$. The domain is a peninsular region flanked by Himalayan Mountains in the north. The first nested domain (D2) constitutes northern India region with resolution of $6 \mathrm{~km}$. The second nested domain (D3), which is the area under analysis, covers the city of National Capital Region of Delhi and surroundings with a domain resolution of $2 \mathrm{~km}$ centered at $28.52^{\circ} \mathrm{N}$ and $77.12^{\circ} \mathrm{E}$. D3 lies in the sub-tropical climate zone (Köppen classification: Cwa). Geologically, this region is bounded by the Indo-Gangetic alluvial plains in the North and East, by Thar Desert in the West and by old Aravalli hill ranges in the South. There is a ridge trending along NNESSW direction which constitutes a small area of Delhi's terrain which is otherwise generally flat. Seasonally, the year can be divided into four main periods. Summer is experienced in the months of March-June followed by monsoon months of July, August, and September. Postmonsoon months are October and November while the period of December-February constitutes the winter season. The maximum temperature ranges from 41 to $45{ }^{\circ} \mathrm{C}$ in peak summer season and the minimum temperature in winter season is in the range of $3-6{ }^{\circ} \mathrm{C}$ in coldest period of December-January.

The simulation was carried out for a time period of 5 days, that is, 24 May 20080000 UTC-29 May 0000 UTC. First $24 \mathrm{~h}$ in each simulation was considered as spin-up and remaining hours were used for analysis. As per Mohan and Sati (2016), simulations for shorter duration (2-5 days) produce better results in comparison to longer duration. Physical parameterization schemes implemented in the model include Lin scheme (Lin et al.

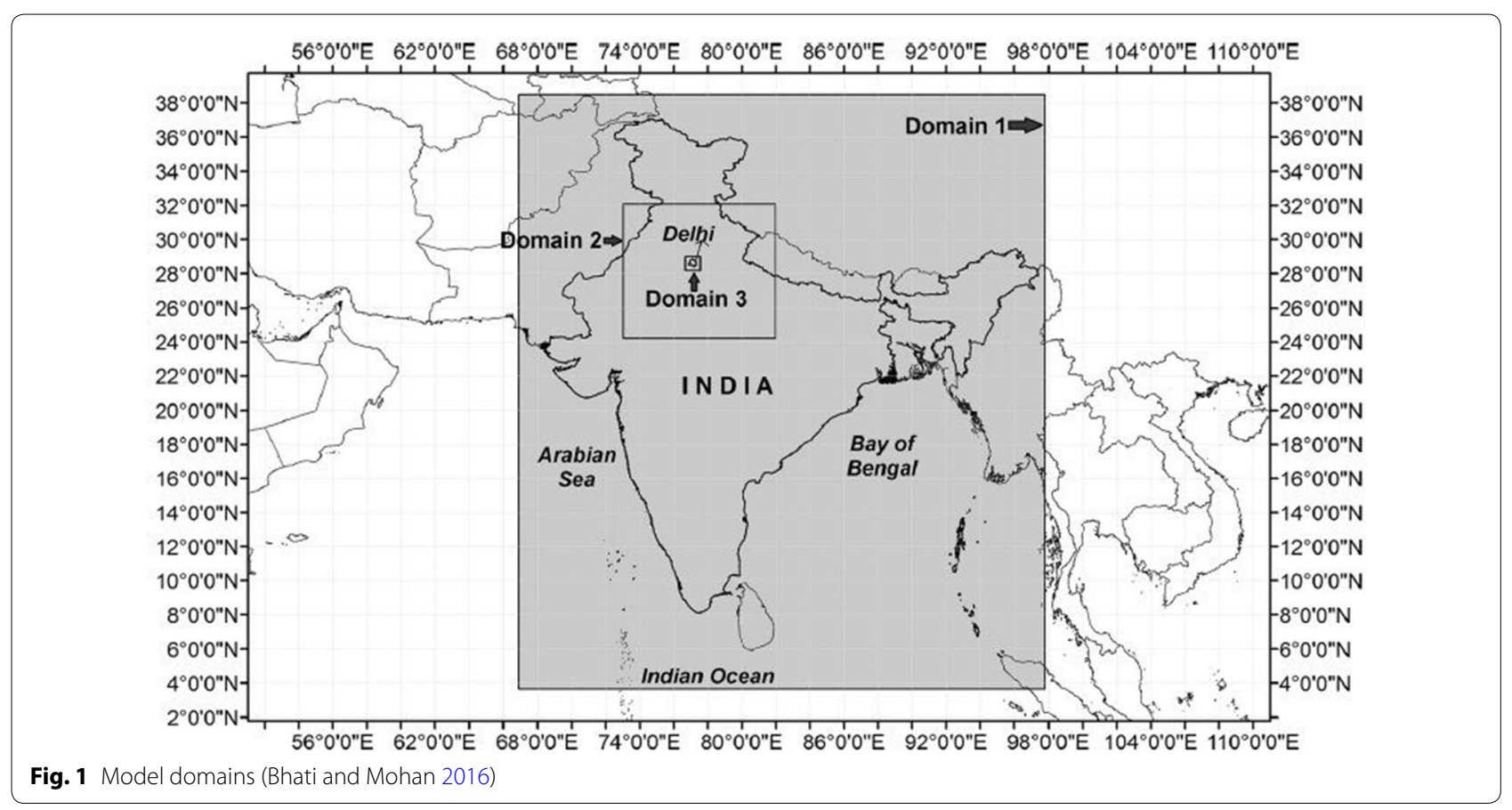


1983) for microphysics, rapid radiative transfer model (RRTM) scheme for long wave radiation (Mlawer et al. 1997), Dudhia scheme for short wave radiation (Dudhia 1989), Noah land surface model (Tewari et al. 2004), Pleim-Xiu surface layer (Pleim 2006), asymmetric convection model (ACM2) planetary boundary layer (Pleim 2007), and Kain-Fritsch cumulus parameterization (Kain 2004). These options were selected based on earlier studies over the Delhi region (Mohan and Bhati 2011; Bhati and Mohan 2016). Final analysis data (FNL) from the National Centers for Environmental Prediction (NCEP) were used as input for initial and boundary conditions to the model. FNL data are operational global analysis data available on $1^{\circ} \times 1^{\circ}$ grids at six-hourly time steps (Banks et al. 2016).

\section{Description of field campaign and data for model validation Field campaign}

In May 2008, a field campaign was conducted in National Capital Region of Delhi to understand the existing urban heat island scenario. The field campaign was conducted from 25 May-28 May 2008 (Mohan et al. 2012) which belongs to summer season in Delhi. As per the ClimateNormals of Delhi (IMD 2017), the average maximum temperature during the month of May is about $40{ }^{\circ} \mathrm{C}$ while the average minimum temperature is about $26{ }^{\circ} \mathrm{C}$. During the period of field campaign, the minimum temperatures ranged from about 20 to $22{ }^{\circ} \mathrm{C}$ while the maximum temperatures ranged from 33 to $37^{\circ} \mathrm{C}$. The morning hours of 26th May experienced rainfall for duration of roughly two hours from 9:00 a.m. to 11:00 a.m. The rest of the period of field campaign did not witness any event of precipitation within the study area.

27 micrometeorological stations were set up at various sites throughout the Delhi region for continuous measurement of air temperature and relative humidity. These stations included 19 urban stations (sites with $>40 \%$ built-up fraction) and 8 non-urban stations (natural and cultivated green areas, open areas and riverside areas). In addition, 3 weather stations were also installed to give information about various other meteorological parameters such as wind speed and direction, atmospheric pressure, and solar radiation. Measurements from field campaign have been utilized as data for validation and evaluation of WRF model in the present study.

\section{Evaluation of model performance}

Model performance has been evaluated using statistical parameters such as mean bias (MB), mean absolute error (MAE), root mean squared error (RMSE) and index of agreement (IoA). While MB, MAE and RMSE measure the error or deviation between observed and simulated values, index of agreement determines the degree to which magnitudes and signs of the observed value are related to the predicted values and, in other words, the trend relationship. Hit rate has been computed as percentage of simulated UHIs with a value within $\pm 2{ }^{\circ} \mathrm{C}$ of corresponding observed value (Cox et al. 1998). Thus, hit rate serves as an indicator of models' ability to capture in situ UHIs (Bhati and Mohan 2016). Emery et al. (2001) discussed that evaluation benchmarks of a meteorological model should be based on typical performance of meteorological models that have been accepted and used in the past studies. Based on their simulation experiments and literature review, they proposed a statistical benchmark which is $\mathrm{MAE} \leq 2{ }^{\circ} \mathrm{C}$ and $\mathrm{IoA} \geq 0.8$. These benchmarks have subsequently been used in many model performance evaluation studies (Borge et al. 2008; Gilliam and Pleim 2010, Shimadera et al. 2011; Kumar et al. 2012; Hernández-Ceballos et al. 2013; Vázquez et al. 2014; Bhati and Mohan 2016).

\section{Results and discussion \\ Difference in land use/land cover}

As stated earlier in "Description of land use datasets" section, there has been a significant change in land use/ land cover (LULC) over many areas in Delhi owing to progressive urbanization. Figure 2 compares the four LULCs (USGS, MODIS, modified and UCM) as simulated in model runs. Similar colors have been given to similar land use. Built-up and urban category are clearly dominant in MODIS land use and include vast swathes of Delhi and surrounding region.

Mohan et al. (2011) evaluated the LULC changes and urban expansion in Delhi city from 1997 to 2008 based on the analysis of LISS-III satellite images. In 2008, builtup area in Delhi was found to occupy about $52 \%$ followed by cultivated vegetation (20\%), natural vegetation (14\%), sandy area (12\%) and water bodies (2\%). Distribution of different LULC types in different terrestrial datasets is given in Table 1. It can be seen that modified and UCM LULC is closest to that observed by Mohan et al. (2011) based on LISS3 image of study area. Urban areas are under-represented in USGS LULC and grossly over-represented in MODIS LULC.

\section{Near surface temperature}

Figure 3 displays time series of temperature at $2 \mathrm{~m}$ derived from model simulations carried out with the four different land use inputs. Here, urban areas include stations of field campaign with built-up infrastructure while non-urban areas include green areas (natural and cultivated), open areas (sandy/barren/sparsely vegetated) and riverside areas. In general, the model shows overestimation of temperature with MODIS temperatures 

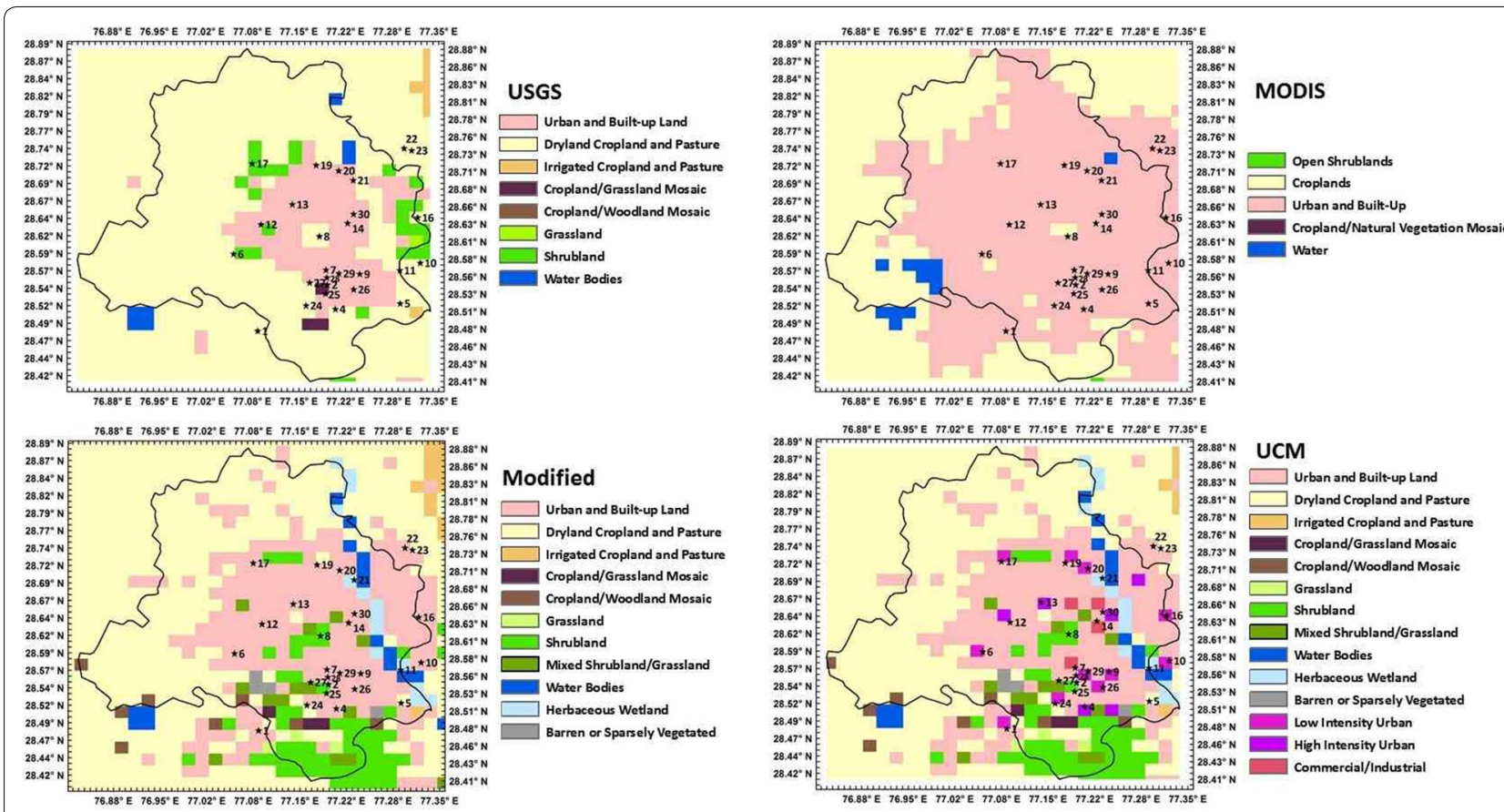

Fig. 2 Representation of different land use/land cover in four model simulations

Table 1 Distribution of different land use types in input terrestrial data sets for WRF model

\begin{tabular}{|c|c|c|c|c|}
\hline Type & USGS (\%) & MODIS (\%) & $\begin{array}{l}\text { Modified } \\
\text { and UCM (\%) }\end{array}$ & $\begin{array}{l}\text { Satellite (Mohan } \\
\text { et al. 2011) (\%) }\end{array}$ \\
\hline Urban (built-up/high-low residential/commercial/industrial) & 25.17 & 90.66 & 49.83 & 52 \\
\hline \multicolumn{5}{|l|}{ Non-urban } \\
\hline Cultivated green (cropland and pastures) & 59.03 & 6.08 & 27.43 & 20 \\
\hline Natural green (grassland/scrubland/woodland) & 14.58 & 0.83 & 18.92 & 14 \\
\hline Water & 1.22 & 2.43 & 3.13 & 12 \\
\hline Barren/sparsely vegetated/sandy & 0.00 & 0.00 & 0.69 & 2 \\
\hline
\end{tabular}

exhibiting highest overestimation for urban and nonurban areas. Temperatures with modified LULC are closer to observed temperatures in comparison to USGA and MODIS. However, introduction of urban canopy in the model significantly improves the model performance.

Table 2 shows statistical evaluation of different sites clubbed as per their land use. Both modified land use and UCM simulations perform better than USGS and MODIS simulations. It is noteworthy that the inclusion of urban canopy features improves the performance of the model not only for urban areas but also for nonurban areas (green, open and riverside).

Importance of updated land use can be better understood from Fig. 4 which shows two statistical parameters viz. mean error and index of agreement for 2-m temperature at some individual monitoring stations of the field campaign. Names in gray shade indicate non-urban stations. The maximum desirable error and the minimum desirable index of agreement are indicated by straight lines. It can be seen that there is substantial improvement for both MAE and IoA for stations which have been modified for their actual land use based on ground truth in comparison to USGS as well as MODIS. Urban canopy features in the model lead to improvement of model performance for all stations. However, even with UCM the model performance is not as per recommended benchmarks of Emery et al. (2001). This could partly be attributed to unusual lowering of temperatures due to unseasonal showers on 26th May 2008. The rainfall was not represented in the input $1^{\circ}$ FNL data and thus was not captured by the model. Figures 5 and 6 show performance of model for relative humidity. The model has a tendency for underestimation of relative humidity which has earlier been 


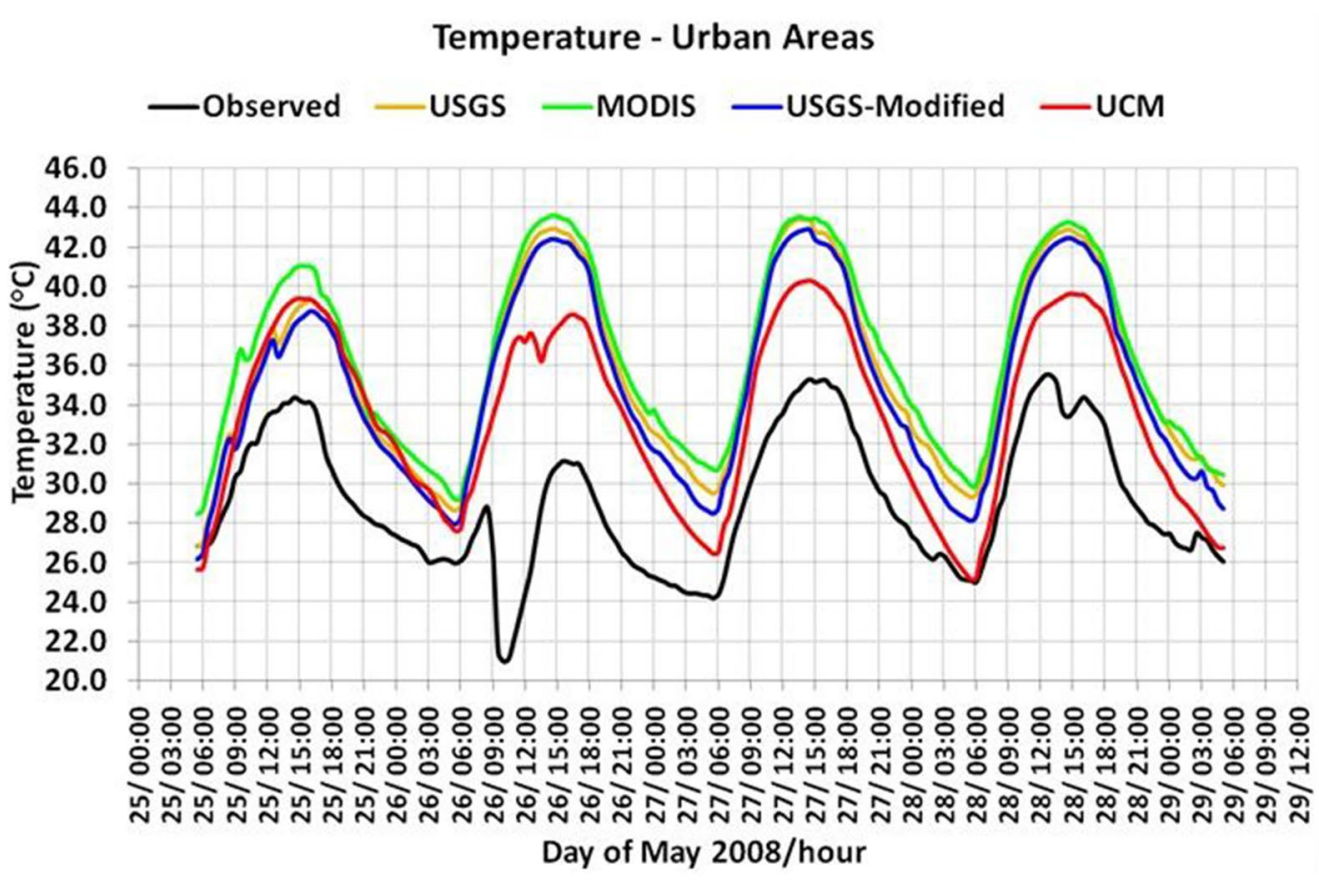

Temperature - Non Urban Areas

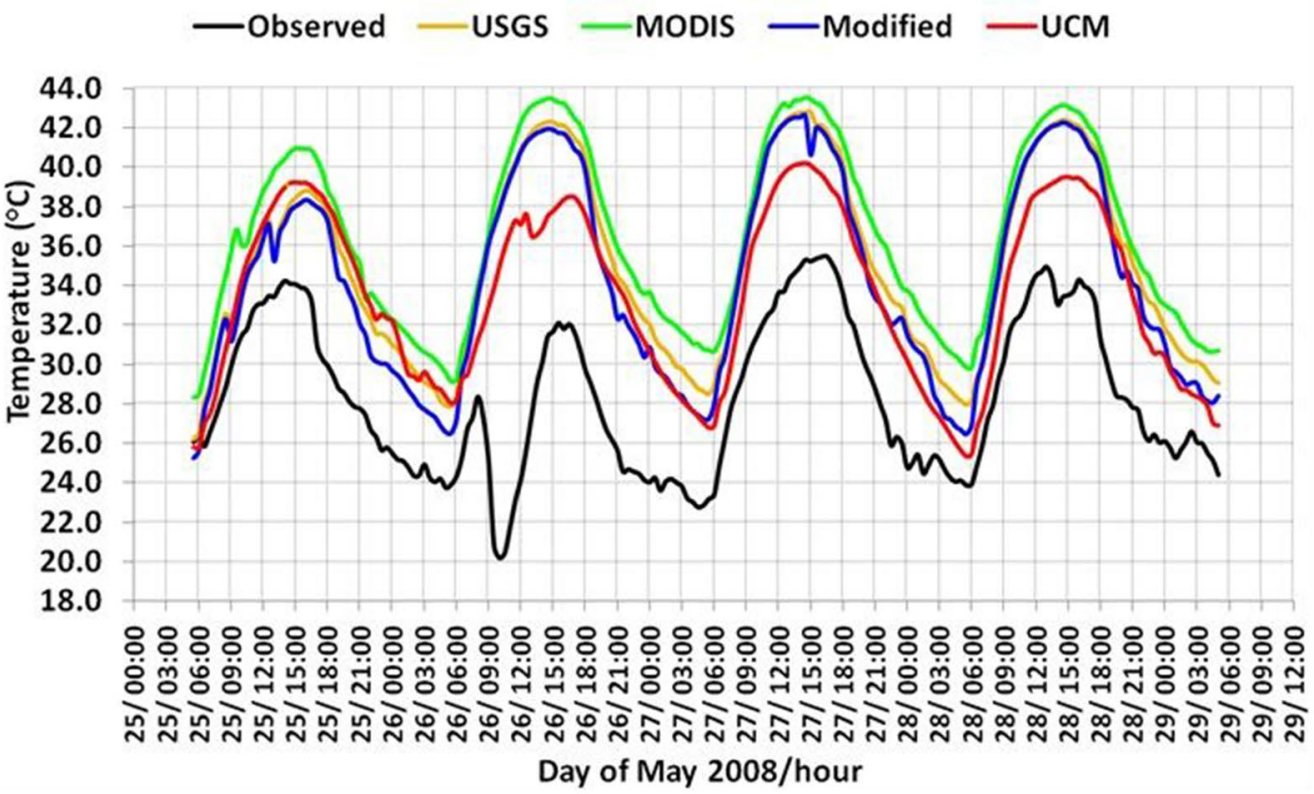

Fig. 3 Time series of near surface temperature 25-28 May 2008 for WRF simulations with different input LULC

observed for the study region for other time periods as well (Mohan and Bhati 2011). This can be linked to tendency of model to over-estimate the near surface temperatures. Even though inclusion of UCM improves the statistical performance of model (Fig. 5), statistical benchmarks for error and index of agreement are still not achieved. However, as mentioned earlier, gaps in model performance for humidity could be due to the local presence of high moisture levels pre- and postprecipitation event which was probably not captured in global FNL data.

\section{Improvement of model estimates with bias correction}

As shown in "Near surface temperature" section, WRF has shown a consistent tendency to overestimate temperature and underestimate relative humidity. This 
Table 2 Statistical evaluation of WRF model performance for temperature for different types of observation sites

\begin{tabular}{|c|c|c|c|c|c|c|}
\hline Sites & Input LULC & MB & MAE & RMSE & COR & IoA \\
\hline \multirow[t]{4}{*}{ Urban } & USGS & 5.16 & 5.17 & 5.44 & 0.95 & 0.69 \\
\hline & MODIS & 6.13 & 6.13 & 6.30 & 0.97 & 0.64 \\
\hline & Modified & 4.48 & 4.49 & 4.81 & 0.95 & 0.73 \\
\hline & UCM & 3.38 & 3.41 & 3.87 & 0.95 & 0.81 \\
\hline \multirow[t]{4}{*}{ Green } & USGS & 6.02 & 6.03 & 6.31 & 0.91 & 0.66 \\
\hline & MODIS & 7.82 & 7.82 & 7.99 & 0.93 & 0.58 \\
\hline & Modified & 6.00 & 6.01 & 6.28 & 0.92 & 0.67 \\
\hline & UCM & 4.99 & 5.02 & 5.29 & 0.94 & 0.73 \\
\hline \multirow[t]{4}{*}{ Open } & USGS & 4.83 & 4.86 & 5.18 & 0.93 & 0.73 \\
\hline & MODIS & 6.60 & 6.60 & 6.77 & 0.94 & 0.64 \\
\hline & Modified & 4.16 & 4.23 & 4.62 & 0.92 & 0.77 \\
\hline & UCM & 3.41 & 3.50 & 4.05 & 0.91 & 0.82 \\
\hline \multirow[t]{4}{*}{ River } & USGS & 4.90 & 4.92 & 5.20 & 0.94 & 0.72 \\
\hline & MODIS & 6.49 & 6.49 & 6.65 & 0.96 & 0.63 \\
\hline & Modified & 4.35 & 4.38 & 4.73 & 0.94 & 0.76 \\
\hline & UCM & 3.66 & 3.71 & 4.10 & 0.92 & 0.79 \\
\hline
\end{tabular}

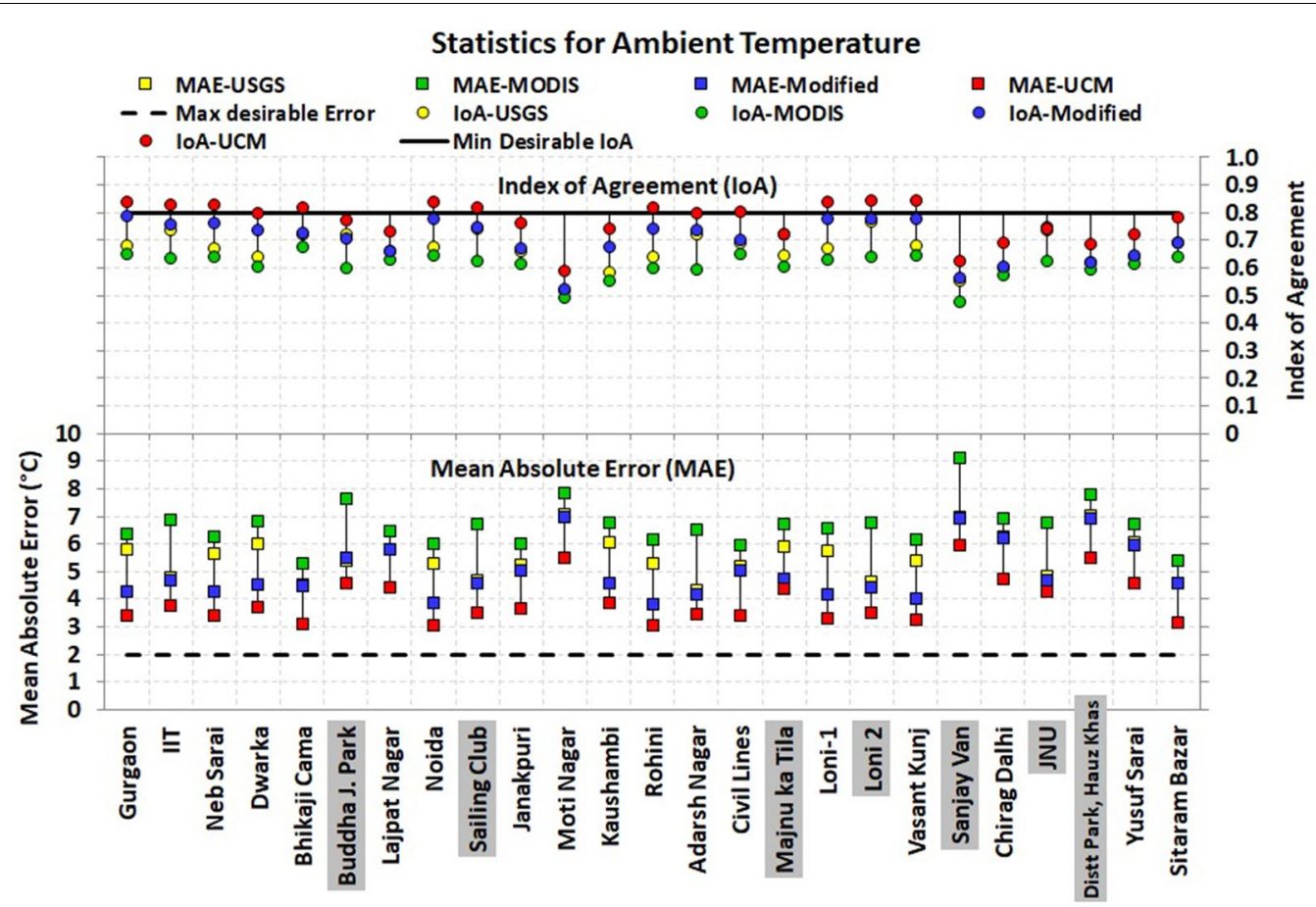

Fig. 4 Index of agreement (top) and mean absolute error (bottom) for some individual sites for near surface temperature. Shaded names indicate non-urban stations

behavior has been observed in other studies too for Delhi region for varying simulation time periods. Gunwani and Mohan (2017) reported a bias of $3.1-4.9^{\circ} \mathrm{C}$ using various PBL schemes in WRF. Sati and Mohan (2017) also observed a major trend of overestimation of temperature with mean bias ranging between 0.2 and $1.9{ }^{\circ} \mathrm{C}$. Mohan and Gupta (2018) applied WRF-Chem over Delhi region and found RMSEs of the range $2.5-4{ }^{\circ} \mathrm{C}$ in the overestimation of temperature by model. These case studies provide a ground for considering simulation outputs after correcting the inherent bias in them. Thus, a preliminary post-processing correction in model results was done by 
Statistics for Relative Humidity, 25-28 May 2008

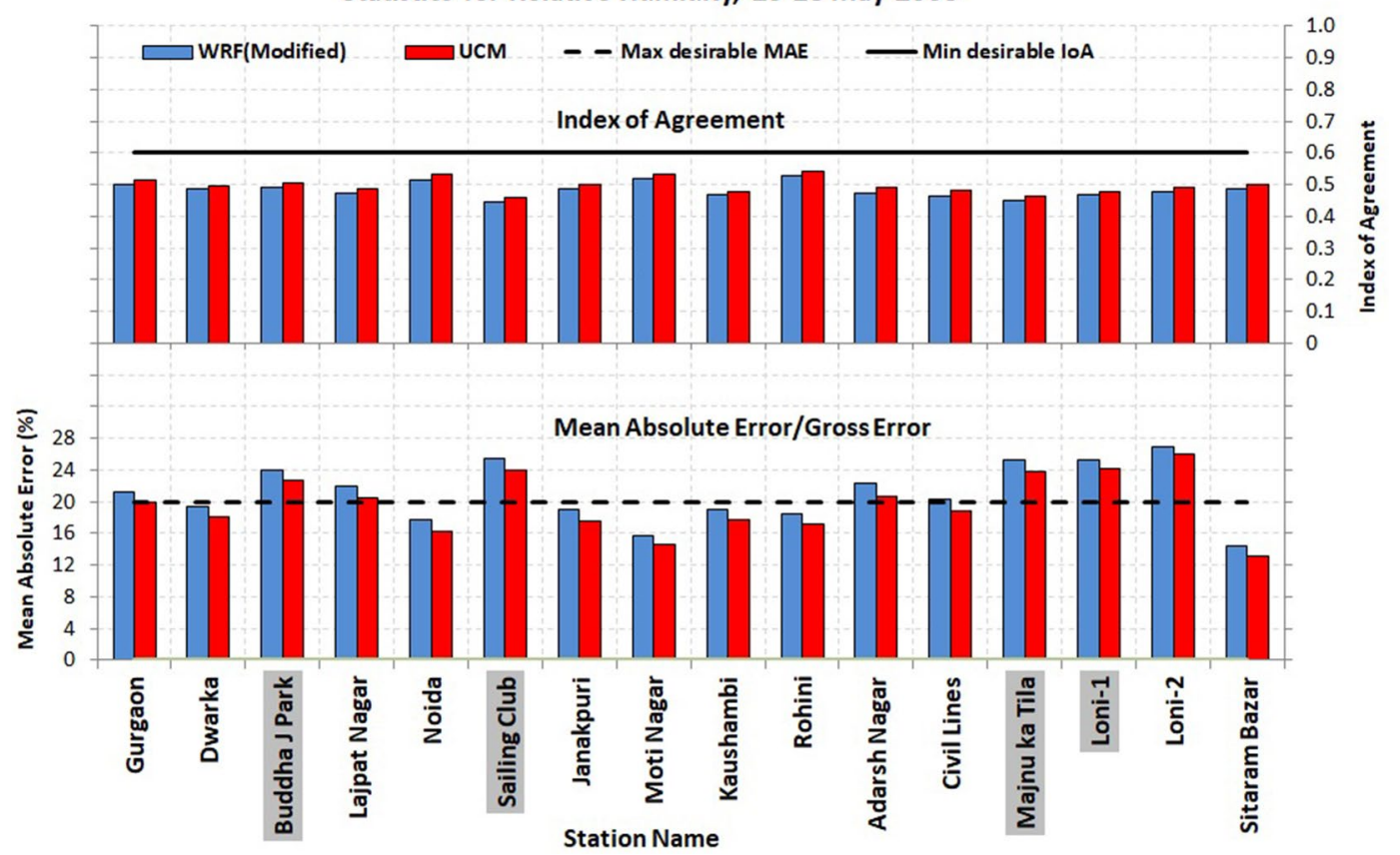

Fig. 5 Index of agreement (top) and mean absolute error (bottom) for some individual sites for relative humidity. Shaded names indicate non-urban stations

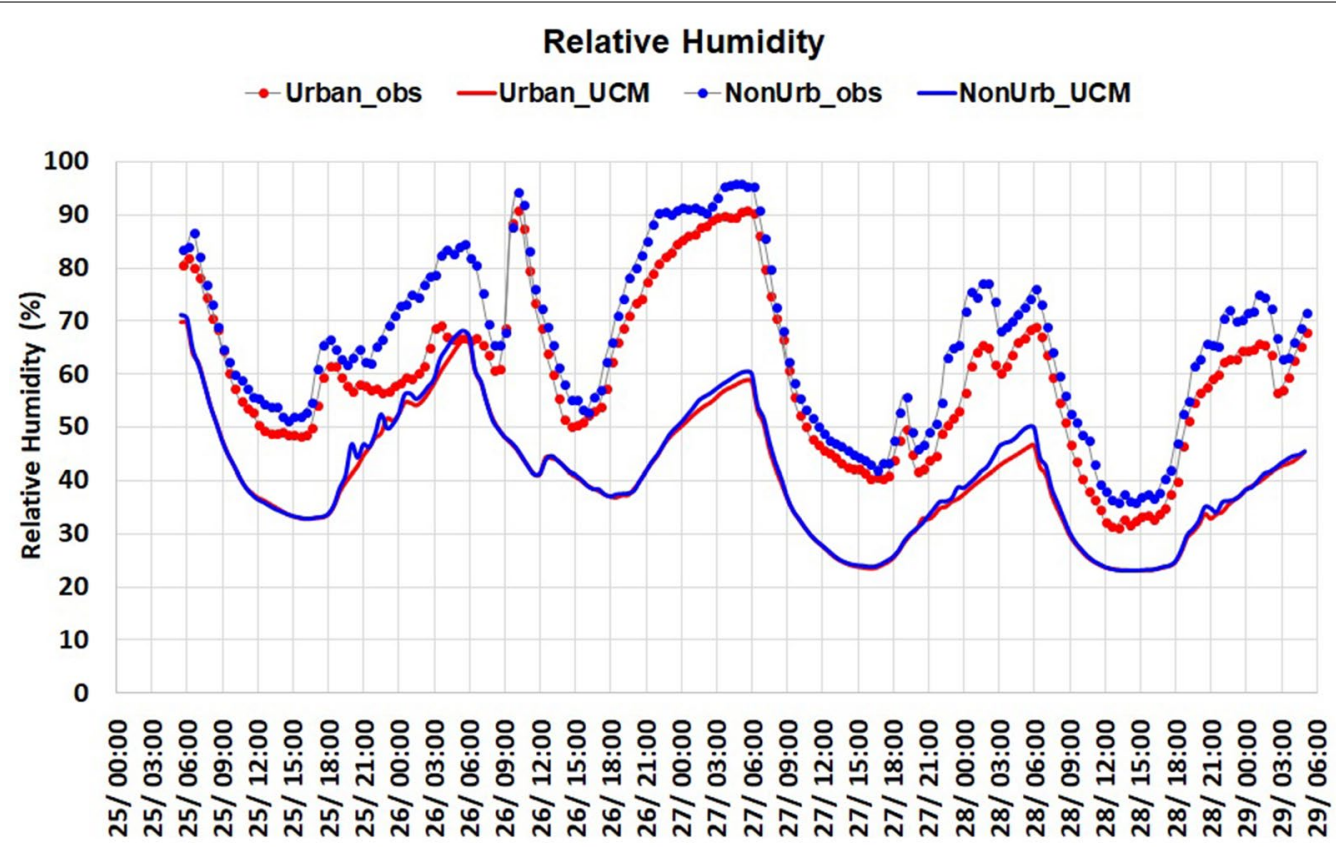

Day of May 2008/ Time

Fig. 6 Time series of relative humidity 25-28 May 2008 for WRF simulations with UCM 
eliminating an average error. A detailed sensitivity analysis and performance evaluation for WRF model were carried out for the study region in both summer and winter conditions in an earlier study (Mohan and Bhati 2011) in which an average RMSE of $2.78{ }^{\circ} \mathrm{C}$ for temperature and $11.23 \%$ for relative humidity was observed. Hence, an average overestimation error of $2.78{ }^{\circ} \mathrm{C}$ for temperature and underestimation error of $11.23 \%$ for relative humidity was corrected in model results. Table 3 displays improvement in model performance statistics after correction in model bias.

\section{Intra-city temperature variation: urban heat island effect}

It has been discussed in "Near surface temperature" section that land use-land cover has significant influence on WRF model performance of near surface temperatures. Therefore, it is expected to have similar influence on temperature variation and consequently urban heat island intensity distributions within the study area. Recently, intra-city temperature variations have been garnering more attention (Martin et al. 2014; Bhati and Mohan 2016) in comparison to classical approach of estimating UHI where comparisons were carried out against a rural area near the city. In the present study, Buddha Jayanti Park (station no. 8 of field campaign) which lies within Delhi ridge area has been considered as reference point for computing heat island intensity. Figures 8, 9, 10, and 11 display spatial distribution of heat island intensity. The heat island intensity has been represented as relative urban heat island intensity. Relative UHI helps in determining whether the model was able to capture high UHI zones or not or how good is the distribution pattern of simulated UHI when compared with the observed hotspots. Relative UHI is defined as (Bhati and Mohan 2016):

$$
\text { Relative } \operatorname{UHI}(x, y)=\frac{\mathrm{UHI}(x, y)}{D}
$$

$$
D=\max \left|\operatorname{UHI}\left(x_{i}, y_{i}\right)\right|
$$

where the relative $\mathrm{UHI}$ of a point $x, y$ in a domain is estimated by dividing UHI at that point with a standardizing factor $D$. $D$ is the maximum of absolute values of UHIs of all points $\left(x_{i}, y_{i}\right)$ in the given domain.

\section{Near surface UHI}

Diurnal range of maximum UHI for simulations with four different LULC has been shown in Fig. 7. Magnitudes of maximum UHI are least for MODIS and UHIs computed from modified and UCM simulations perform well. UCM UHIs are lower than modified UHIs during daytime due to shading effects of urban canopy. However, they get closer to observed UHIs during nighttime as the phenomenon of heat trapping by urban canopy is not captured in other simulations. Daytime observed UHIs in the city are higher than simulated UHIs probably due to anthropogenic heat which has not been accounted for in present study. Influence of change in LULC on model performance for estimation of intra-spatial temperature gradients is further explored in Table 4 which displays statistical evaluation parameters for maximum heat island intensities for among urban areas as well as non-urban areas with respect to the reference site. Modified and UCM UHIs have lowest errors and highest correlations and hit rate for both urban areas and non-urban areas.

Figure 8 displays distribution of UHI based on air temperatures for nighttime for the study area based on air temperatures from simulations with all four different land use. The maximum UHI as computed has also been indicated in the figure. In terms of absolute magnitude of maximum UHI, modified and UCM coupled simulations perform better than USGS and MODIS simulations. There is the presence of large cool zones in USGS distribution. In MODIS distribution, a large extent of study area comes

\begin{tabular}{|c|c|c|c|c|}
\hline & \multicolumn{2}{|l|}{ Temperature } & \multicolumn{2}{|c|}{ Relative humidity } \\
\hline & Urban areas & Non-urban areas & Urban areas & Non-urban areas \\
\hline \multicolumn{5}{|l|}{ Mean bias } \\
\hline Pre-bias correction & $2.97^{\circ} \mathrm{C}$ & $4.22^{\circ} \mathrm{C}$ & $-18.87 \%$ & $-24.89 \%$ \\
\hline Post-bias correction & $0.29^{\circ} \mathrm{C}$ & $1.46^{\circ} \mathrm{C}$ & $-7.64 \%$ & $-13.66 \%$ \\
\hline \multicolumn{5}{|l|}{ RMSE } \\
\hline Pre-bias correction & $3.87^{\circ} \mathrm{C}$ & $4.48^{\circ} \mathrm{C}$ & $21.98 \%$ & $27.46 \%$ \\
\hline Post-bias correction & $2.09^{\circ} \mathrm{C}$ & $2.52^{\circ} \mathrm{C}$ & $11.77 \%$ & $16.64 \%$ \\
\hline \multicolumn{5}{|l|}{$\mathrm{loA}$} \\
\hline Pre-bias correction & 0.81 & 0.78 & 0.49 & 0.45 \\
\hline Post-bias correction & 0.87 & 0.82 & 0.62 & 0.56 \\
\hline
\end{tabular}

Table 3 Statistical evaluation of UCM simulations after bias improvement 


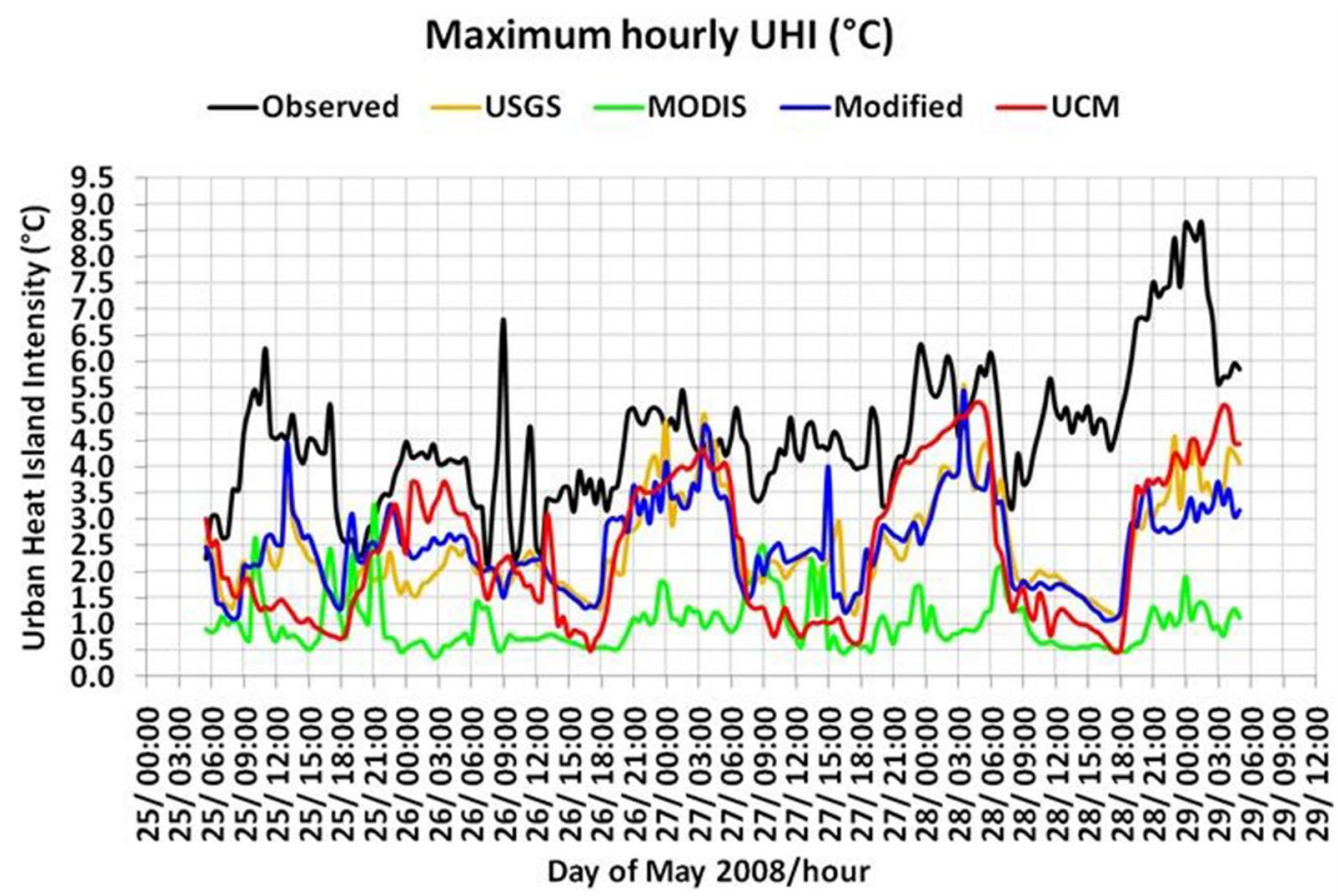

Fig. 7 Time series of hourly maximum UHI

under similar relative UHI range which is because of dominance of the urban LULC in the land use data. Though absolute magnitude of maximum UHI in UCM is closer to observed UHI, in terms of hotspot distribution, modified pattern is closer to observed distribution. Daytime distribution of heat island intensities can be seen in Fig. 9 .

\section{Surface UHI}

Figures 10 and 11 display spatial distribution of relative surface heat island intensity from four LULC-based simulations along with observed distributions for nighttime and daytime, respectively. Observed UHIs have been estimated from land surface temperatures (LST) derived from MODIS-Terra satellite available as 8-day average LSTs in Monsoon Asia Integrated Regional Study (MAIRS) database (Giovanni 2014). As in case of near surface UHI, both modified and UCM distributions are in better agreement with satellite-derived distribution. The maximum spatial UHI is highest for modified distribution $\left(3.98{ }^{\circ} \mathrm{C}\right)$ but UCM maximum $\left(3.19{ }^{\circ} \mathrm{C}\right)$ is closest to observed maximum UHI $\left(3.22{ }^{\circ} \mathrm{C}\right)$ during nighttime. However, the relative UHI distribution does not match during daytime and there is prevalence of a cool island in UCM distribution. Nonetheless, modification in land use and representation of urban canopies has improved model performance for LST-based UHIs also.

\section{Urban areas and thermal comfort}

The urban heat island effect has a direct relation with thermal comfort. The urban heat island has the potential to prevent the city from cooling down, maintaining

Table 4 Statistical evaluation of maximum UHI for urban and non-urban sites

\begin{tabular}{lllllrll}
\hline Sites & Input LULC & MB & MAE & RMSE & COR & IoA & Hit rate (\%) \\
\hline Urban & USGS & -1.384 & 1.432 & 1.616 & 0.595 & 0.635 & 52.1 \\
& MODIS & -2.501 & 2.506 & 2.877 & -0.237 & 0.412 & 34.0 \\
& Modified & -1.243 & 1.311 & 1.650 & 0.613 & 0.579 & 57.2 \\
Non-urban & UCM & -1.004 & 1.259 & 1.474 & 0.795 & 0.704 & 63.4 \\
& USGS & -0.678 & 0.951 & 1.304 & 0.317 & 0.527 & 66.0 \\
& MODIS & -1.540 & 1.570 & 1.917 & -0.126 & 0.437 & 48.5 \\
& Modified & -0.382 & 0.878 & 1.104 & 0.481 & 0.668 & 67.0 \\
& UCM & -0.318 & 0.875 & 1.072 & 0.529 & 0.677 & 71.1 \\
\hline
\end{tabular}



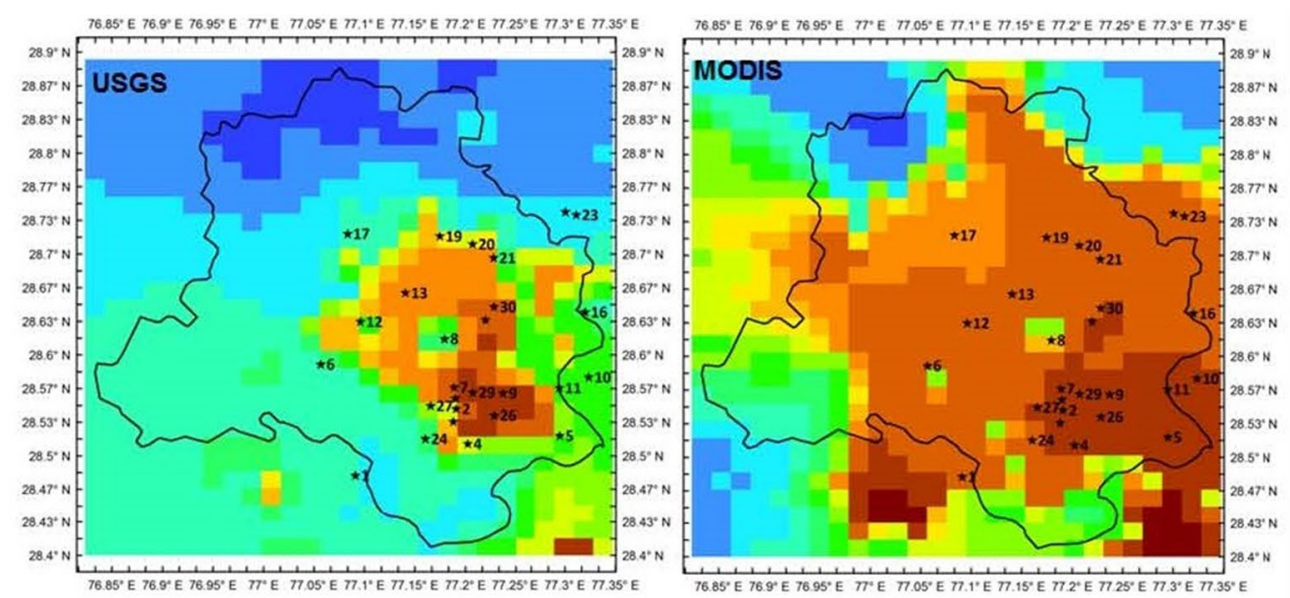

Max UHI

Obs: $3.53^{\circ} \mathrm{C}$

USGS: $3.18^{\circ} \mathrm{C}$

MODIS: $2.91^{\circ} \mathrm{C}$

Modified: $3.38^{\circ} \mathrm{C}$

UCM: $3.63{ }^{\circ} \mathrm{C}$
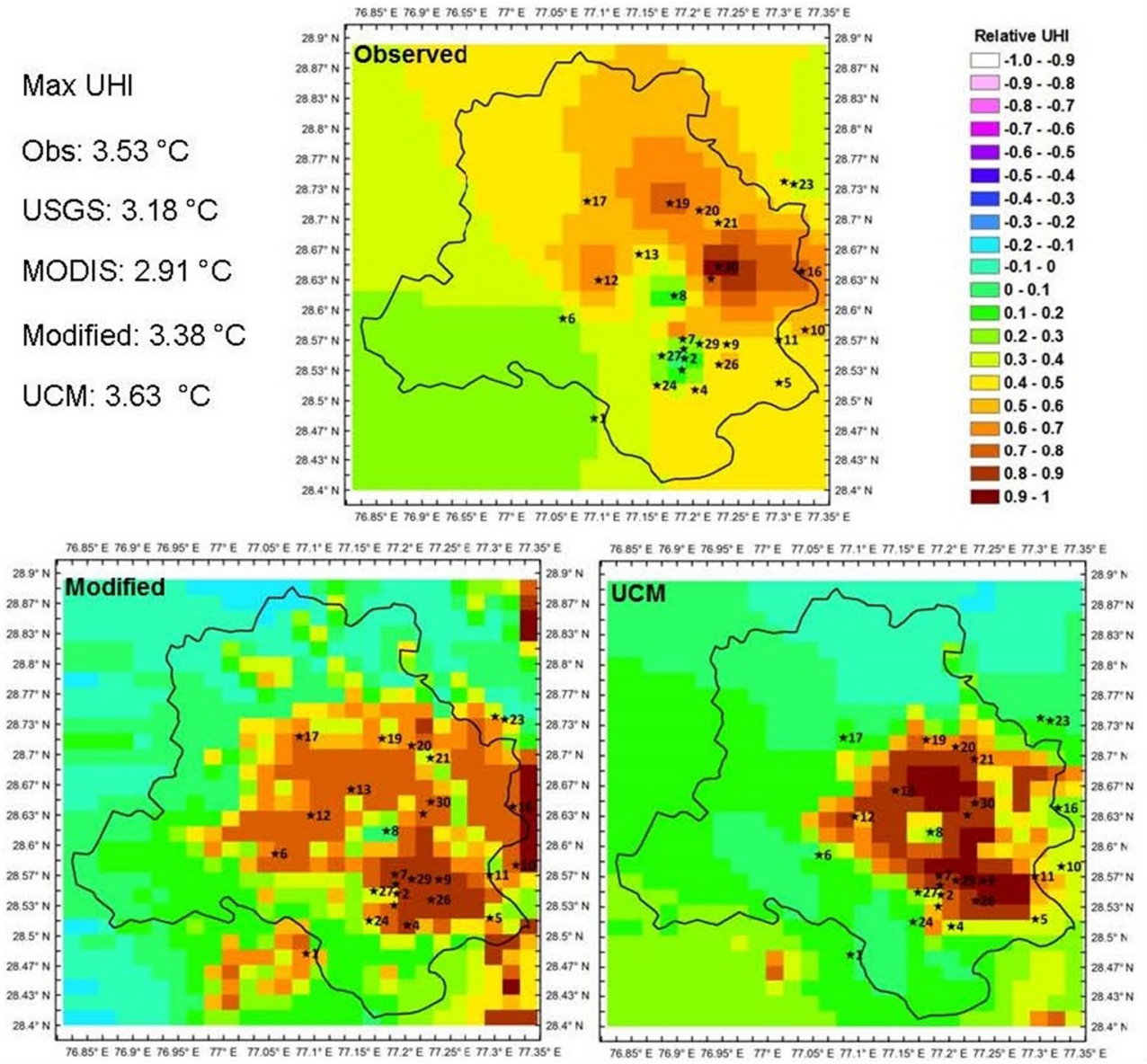

Fig. 8 Nighttime (0300 h local time) distribution of relative heat island intensity

nighttime temperatures at a level that affects human health and comfort (Tan et al. 2009; Lo and Quattrochi 2003; Tomlinson et al. 2011; Mavrogianni et al. 2011). Especially at night, stress caused by heat exhaustion can impact a wide number of diseases which may become worse, particularly in the elderly and children (Laaidi et al. 2012). Further, thermal stress is most relevant to people who spend a substantial time outdoors during a day. These include pedestrians, cyclists, vendors, shopkeepers near roadside and most people from the lower strata of society who live in makeshift houses which can form a significant proportion of population in developing 

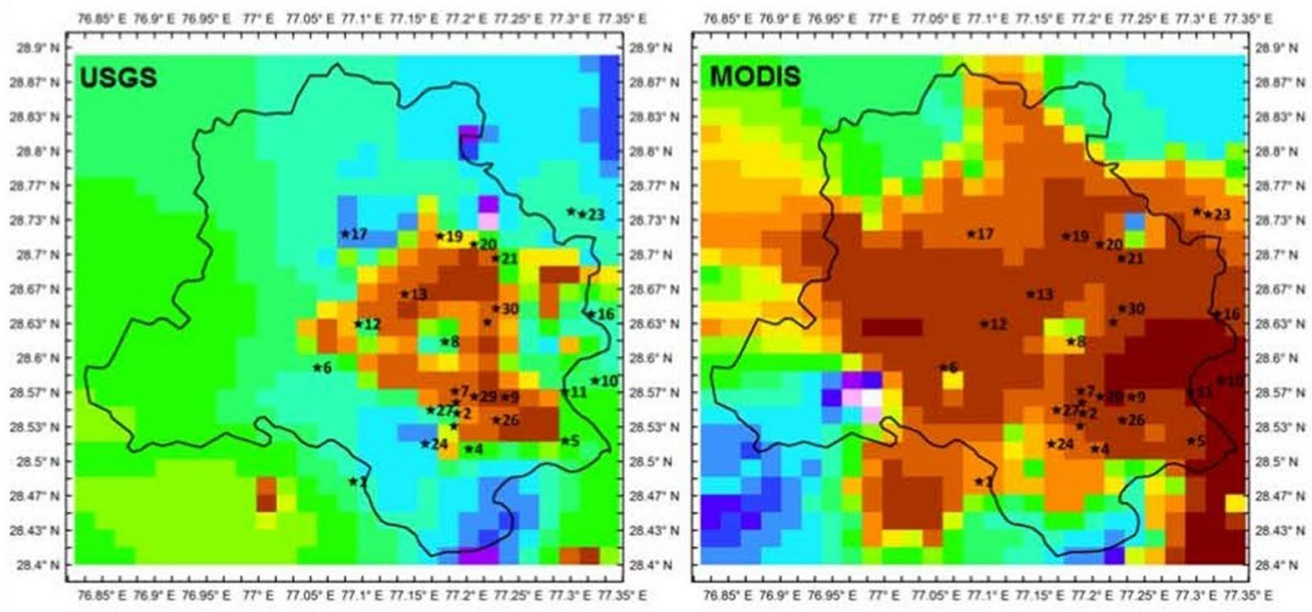

Max UHI

Obs: $3.60^{\circ} \mathrm{C}$

USGS: $1.54^{\circ} \mathrm{C}$

MODIS: $1.64{ }^{\circ} \mathrm{C}$

Modified: $1.42{ }^{\circ} \mathrm{C}$

UCM: $0.45{ }^{\circ} \mathrm{C}$
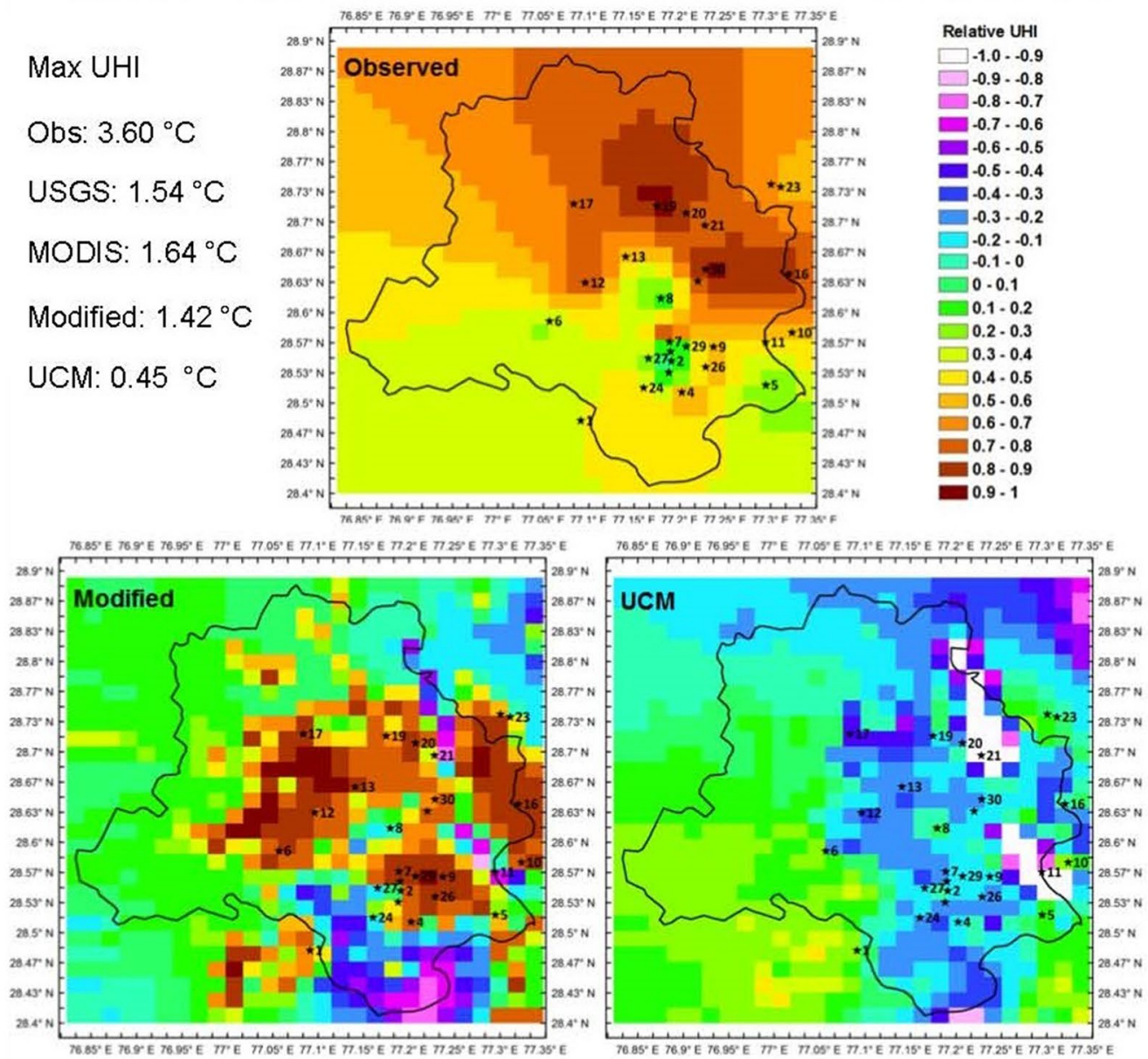

Fig. 9 Daytime (1500 h local time) distribution of relative heat island intensity

countries (Mohan et al. 2014). A large section of this population does not have air conditioning facilities and, thus is most affected by thermal stress-induced discomfort during day as well as night.
There are many indices devised for assessing thermal comfort such as physiological equivalent temperature (PET) (Höppe 1999), Universal Thermal Climate Index (UTCI) (Blazejczyk et al. 2012), and wet bulb globe 


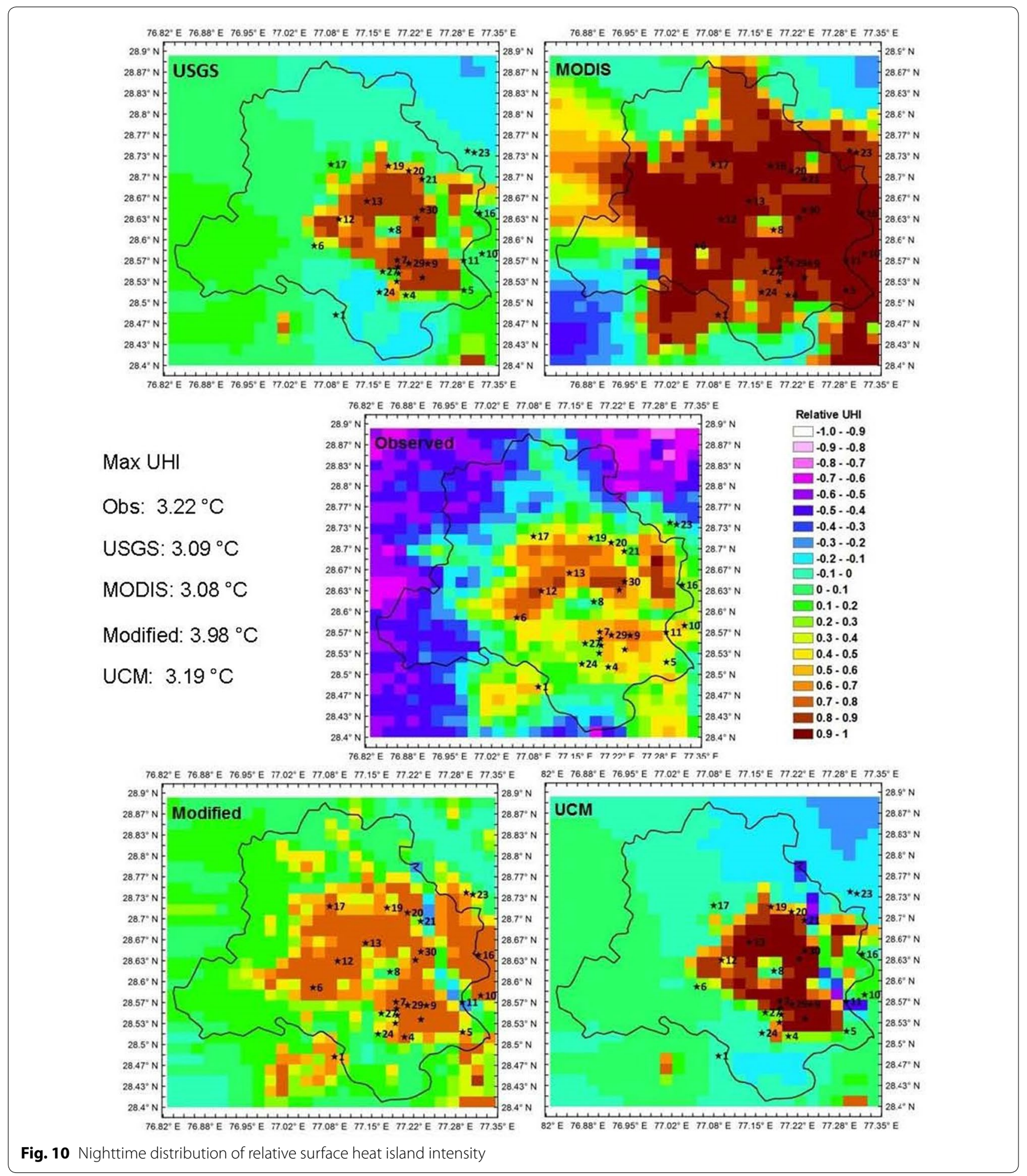

temperature (Yaglou and Minard 1957). Heat Index, also known as apparent temperature of Steadman (1979), is one of the earliest and most commonly used indicators of thermal comfort and incorporates the effect of temperature and relative humidity. Heat Index is basically the temperature that a human body 'feels' under given 


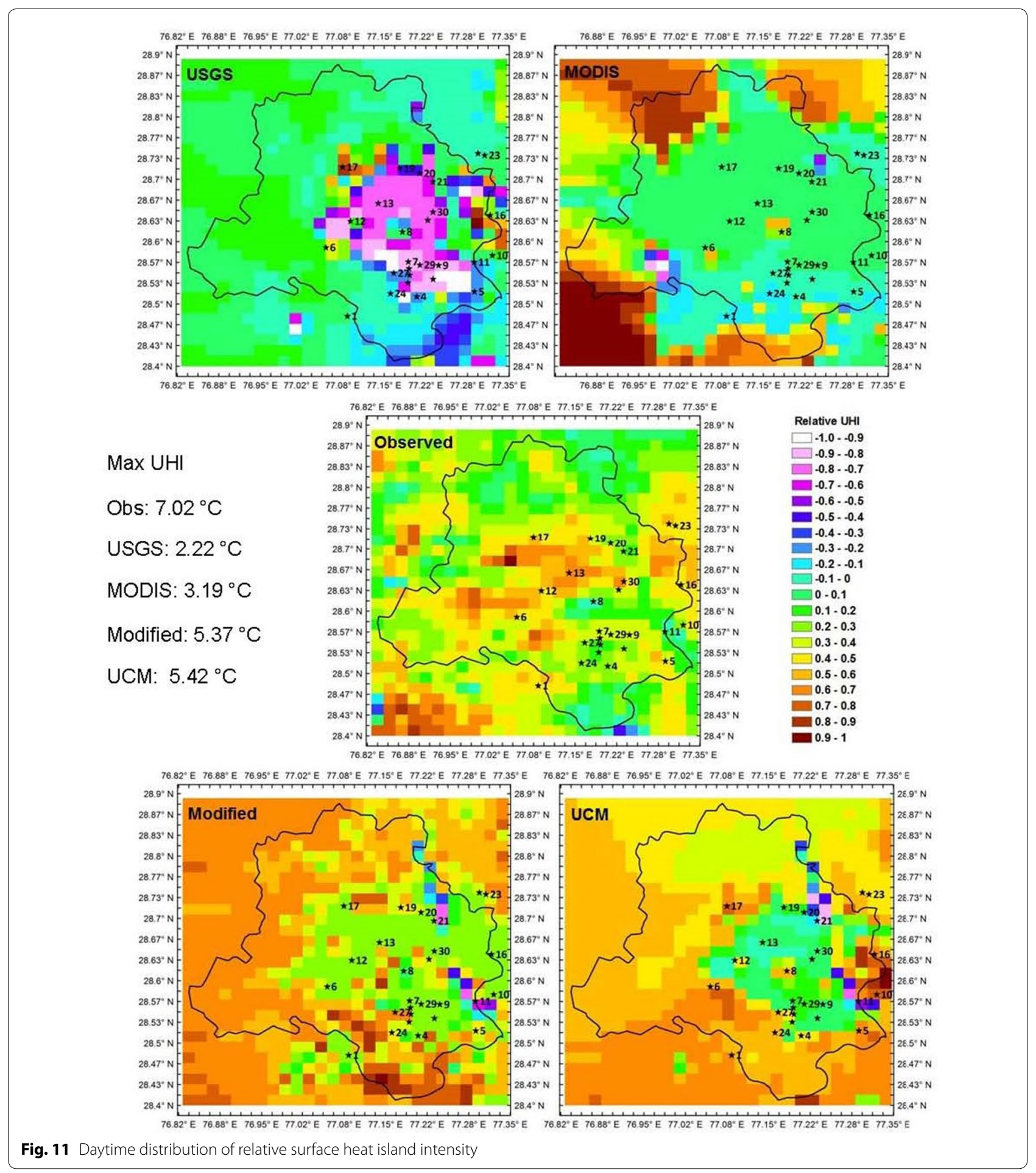


meteorological conditions. Heat Index is calculated as (Rothfusz 1990):

$$
\begin{aligned}
\mathrm{HI}= & -42.379+2.04901523 * T+10.14333127 * \mathrm{RH} \\
& -0.22475541 * T * \mathrm{RH}-0.00683783 * T^{2} \\
& -0.05481717 * \mathrm{RH}^{2}+0.00122874 * T^{2} * \mathrm{H} \\
& +0.00085282 * T * \mathrm{RH}^{2}-0.00000199 * T^{2} * \mathrm{RH}^{2}
\end{aligned}
$$

where $\mathrm{HI}$ is the Heat Index (in ${ }^{\circ}$ Fahrenheit), $T$ is the ambient dry bulb temperature in degrees Fahrenheit and $R$ is the relative humidity (\%). Heat Index has been used in many studies for temperature impact assessment in human morbidity, heat waves and urban heat island effect (Mohan et al. 2014; Hartz et al. 2012; Silva et al. 2010; Yip et al. 2008).

Numerical weather prediction models like WRF help in assessing thermal comfort by means of providing a continuous distribution of spatial data which is limited in case of observations. Further, it is difficult to assess the role of urban canopy in influencing thermal comfort within a city using observational database only. Therein lies the utility of models such as UCM which can be coupled with WRF to analyze thermal comfort without and with canopy effect.

In the present study, Heat Index has been estimated based on the temperature and humidity as simulated using USGS and UCM simulations. Hence, USGS represents WRF simulation with default terrestrial simulations and without urban canopy effect, while UCM represents simulation with updated LULC and incorporation of canopy features. Figure 12 shows spatial distribution of Heat Index at $0400 \mathrm{~h}$ which corresponds to minimum temperature epoch for Delhi during the study period. Conceptually, thermal comfort is applicable for areas where human presence is either norm or can be expected for some time. Hence, all model grids corresponding exclusively to water surface as shown in LULC in Fig. 2 have been excluded from calculation for Heat Index. However, near water grids are considered.

\section{Urban vs non-urban areas}

Figure 12a shows distribution of Heat Index based on USGS simulations while UCM-based Heat Index is displayed in Fig. 12b. It can be seen that non-urban areas (8, $11,21,23,25,28)$ have comparatively lower Heat Index than other urban stations in Fig. 12a. The heat island effect in urban areas leads to higher Heat Index leading to an increase of $1.5-2{ }^{\circ} \mathrm{C}$ in perceived temperature in comparison to non-urban areas.

Similarly, all these non-urban stations experience lower Heat Index in Fig. 12b showing heat index distributions in UCM simulations with the exception of stations
11 and 21 which are riverside stations. As explained in "Modified-USGS land use data (Modified)" and "Field campaign" sections, terrestrial data input to the model was revised to incorporate closer to actual representation of different LULCs. Hence some water bodies were also introduced in UCM simulations. The differential heating of land and water affects the temperature at river side stations. Water bodies, owing to higher heat capacity than land, cool down slowly during nighttime and hence river side stations have higher Heat Index as compared to other non-urban stations.

It may also be noted that some urban stations (such as 1, 6 and 17) also have much lower Heat Index in Fig. 12a. This is because they are represented under non-urban LULCs in USGS simulations. As these stations change to urban in UCM simulation, Heat Index in and around these stations increases in UCM distribution (Fig. 12b).

\section{Canopy effect in thermal comfort}

Figure 12b displays Heat Index as a result of canopy effect in the city. It is clear that the urban canopy effect which intensifies the urban heat island effect also leads to rise in thermal discomfort by increasing Heat Index. There is an increase in Heat Index of about $2.0-2.5{ }^{\circ} \mathrm{C}$ at dense built-up stations such as stations 14 and 30. Further, while non-urban areas maintain lower Heat Index than urban ones, their individual Heat Index values have also increased from USGS simulations. Hence, the impact of urban canopies is experienced meteorologically by nonurban areas too.

Urban heat island-induced thermal discomfort affects people both with and without access to cooling amenities. Higher temperatures have a serious impact on the electricity consumption due to building sector increasing considerably the peak and the total electricity demand. Santamouris et al. (2015) analyzed several past studies dealing with the impact of the ambient temperature on the peak electricity demand and found out that for each degree of temperature increase, the increase of the peak electricity load varies between 0.45 and $4.6 \%$. This corresponds to an additional electricity penalty of about 21 $( \pm 10.4) \mathrm{W}$ per degree of temperature increase and per person. This increase greatly outweighs the otherwise small beneficial decrease in heating demand in winter, especially for sub-tropical/tropical cities. Further, heat released due to operation of electrical cooling devices further exacerbates the heat island effect in the city. This leads to a vicious cycle of urban heat island effect and thermal comfort. Hence, analysis of UHI vis-a-vis thermal comfort is essential with regards to both economic as well as environmental concerns. 


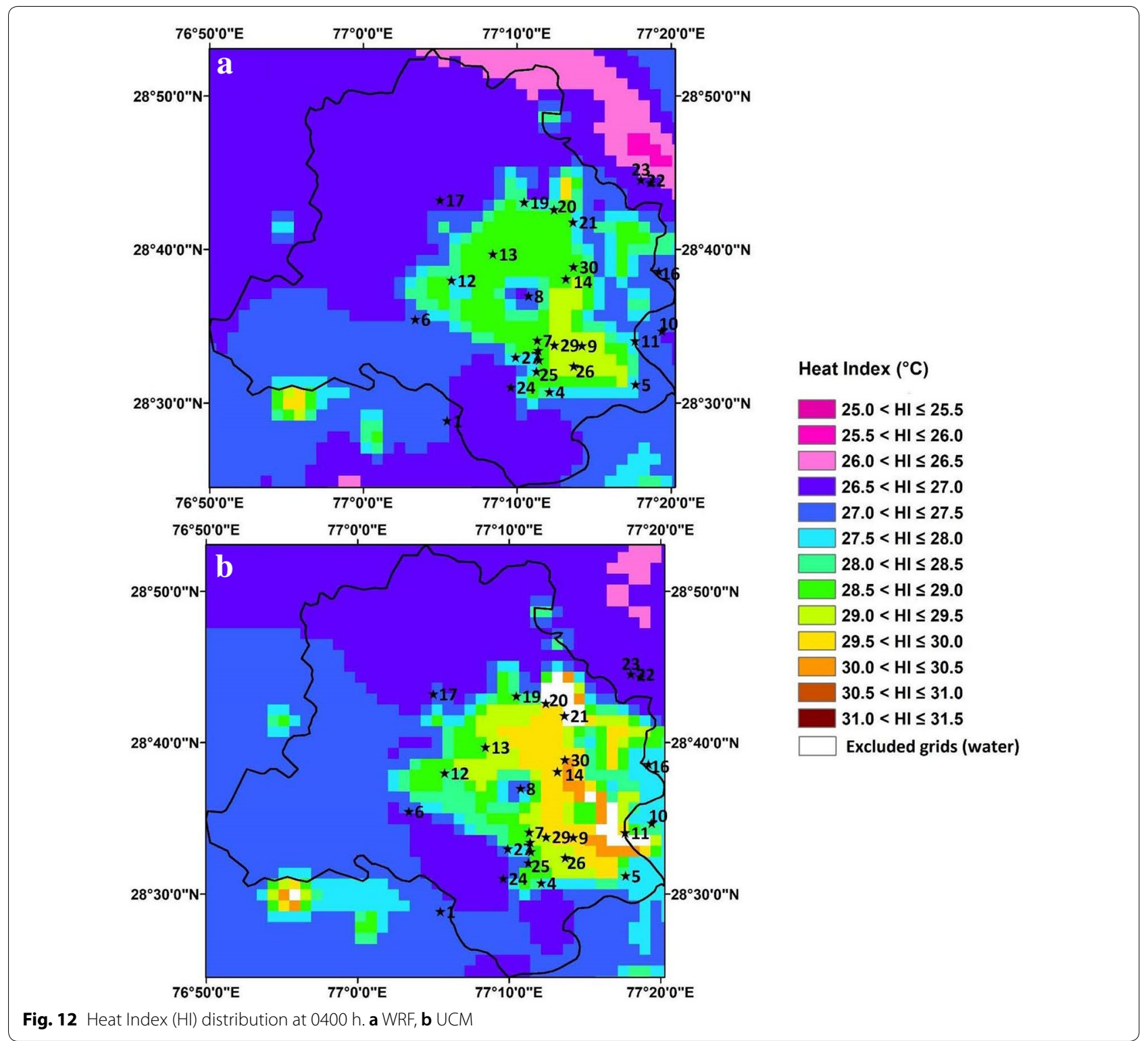

\section{Conclusions}

In the present study, WRF model has been used with three different terrestrial data inputs and finally coupled with urban canopy model to assess the impact of change in LULC on model performance for estimating urban heat island intensities. Major conclusions of the study are as follows:

- Both modified land use and UCM simulations perform better than USGS and MODIS simulations for near surface temperature and relative humidity. Model performance improves not just for urban observation sites but also for non-urban sites.
- Incorporation of urban canopy features really enables simulation of nighttime urban heat island intensity better. However, UCM makes temperature cooler during daytime. Hence UHI distributions do match with observed distribution during daytime. UHI distribution with modified LULC is in closest agreement with observed distribution during daytime.

- Inclusion of urban canopy model has more profound impact on model performance in comparison to various types of land use land cover features.

- The study has revealed the significance of updated LULC inputs in the model along with urban canopy features for better analysis of urban meteorology. 
- A simple and straightforward method of post-processing bias correction has been applied in model results which have led to significant improvement in model performance.

- Simulations with urban canopy model have been used for spatial assessment of impact of urban canopies on thermal comfort in the city. An increase of up to $2.5^{\circ} \mathrm{C}$ in Heat Index has been found at dense built-up areas due to canopy-induced urban heat island effect. This is expected to have socio-economic as well environmental implications.

\begin{abstract}
Abbreviations
WRF: weather research and forecasting model; LULC: land use/land cover; USGS: United States Geological Survey; UCM: urban canopy model; UHI: urban heat island intensity; MB: mean bias; MAE: mean absolute error; RMSE: root mean squared error; loA: index of agreement.
\end{abstract}

\section{Authors' contributions}

Both authors have contributed to data analysis, interpretation of results, writing and preparation of this manuscript. Both authors read and approved the final manuscript.

\begin{abstract}
Acknowledgements
The present study is based on a field campaign carried out as a part of the research project "Implementation and Validation of Numerical Models for Heat Island Studies in Megacity Delhi" supported by the Ministry of Education, Culture, Sports, Science and Technology (MEXT), Japan and conducted jointly by IIT Delhi, IIT Roorkee, and Meisei University, Tokyo. Authors would like to acknowledge HPC facility extended through DST-FIST 2014 Project grant at the Centre for Atmospheric Sciences (IIT Delhi) and supercomputing facility HPC: Padum at IIT Delhi. Some of the analyses in this study were based on data which were acquired as part of the NASA's Earth-Sun System Division and archived and distributed by the Goddard Earth Sciences (GES) Data and Information Services Center (DISC) Distributed Active Archive Center (DAAC). The authors would like to thank the anonymous reviewers for constructive suggestions that have helped in improving the quality of the paper.
\end{abstract}

\section{Competing interests}

The authors declare that they have no competing interests.

\section{Availability of data and materials}

Data used in the study are a part of earlier published studies referred to in the text.

\section{Consent for publication}

Not applicable.

\section{Ethics approval and consent to participate}

Not applicable.

\section{Funding}

Ministry of Education, Culture, Sports, Science and Technology (MEXT), Japan.

Fund for Improvement of Science and Technology Infrastructure, Department of Science and Technology, Government of India.

\section{Appendix}

Statistical measures for model evaluation (Schlünzen and Sokhi 2008).

Following commonly used statistical parameters have been used in the present study. $P_{\mathrm{i}}$ indicates predicted or model-estimated values while observed/measured values are denoted by $O_{\mathrm{i}}$ for each single site and each time $(i) . N$ refers to the number of values in a dataset.

- Mean bias or mean error (MB)

$$
=\left(\frac{1}{N} \sum_{i=1}^{N} P_{i}\right)-\left(\frac{1}{N} \sum_{i=1}^{N} O_{i}\right) \text {. }
$$

- Mean absolute error (MAE) $=\frac{1}{N} \sum_{i=1}^{N}\left|P_{i}-O_{i}\right|$.

- Root mean squared error (RMSE) $=\sqrt{\frac{1}{N} \sum_{i=1}^{N}\left(P_{i}-O_{i}\right)^{2}}$.

- Correlation coefficient (COR)

$$
=\left[\frac{\frac{1}{N} \sum_{i=1}^{N}\left(O_{i}-\bar{O}\right)\left(P_{i}-\bar{P}\right)}{\sigma_{O} \sigma_{P}}\right]
$$

where $\quad \bar{O}=\frac{1}{N} \sum_{i=1}^{N} O_{i} \quad \bar{P}=\frac{1}{N} \sum_{i=1}^{N} P_{i}$ $\sigma_{O}=\sqrt{\frac{1}{N} \sum_{i=1}^{N}\left(O_{i}-\bar{O}\right)^{2}} \sigma_{P}=\sqrt{\frac{1}{N} \sum_{i=1}^{N}\left(P_{i}-\bar{P}\right)^{2}}$.

- Index of agreement (IoA)

$$
=1-\frac{\sum_{i=1}^{N}\left(P_{i}-O_{i}\right)^{2}}{\sum_{i=1}^{N}\left(\left|P_{i}-\bar{O}\right|+\left|O_{i}-\bar{O}\right|\right)^{2}}
$$

Willmott (1981).

- Hit rate $=\frac{1}{N} \sum_{i=1}^{N} n_{i}$ with $n_{i}= \begin{cases}1 & \text { for }\left|P_{i}-O_{i}\right| \leq \mathrm{DA} \\ 0 & \text { else }\end{cases}$

where DA is desired accuracy used as $\pm 2{ }^{\circ} \mathrm{C}$ in the present study.

\section{Publisher's Note}

Springer Nature remains neutral with regard to jurisdictional claims in published maps and institutional affiliations.

Received: 26 March 2018 Accepted: 3 November 2018 Published online: 16 November 2018

\section{References}

Anderson JR, Hardy EE, Roach JT, Witmer RE (1976) A land use and land cover classification system for use with remote sensor data. U.S Geological Survey Professional Paper 964. United States Government Publishing Office, Washington, DC

Banks RF, Tiana-Alsina J, Baldasano JM, Rocadenbosch F, Papayannis A, Solomos S, Tzanis CG (2016) Sensitivity of boundary-layer variables to PBL schemes in the WRF model based on surface meteorological observations, lidar, and radiosondes during the HygrA-CD campaign. Atmos Res 176-177:185-201. https://doi.org/10.1016/j.atmosres.2016.02.024

Bhati S, Mohan M (2016) WRF model evaluation for the urban heat island assessment under varying land use/land cover and reference site conditions. Theor Appl Climatol 126:385-400. https://doi.org/10.1007/s0070 4-015-1589-5 
Blazejczyk K, Epstein Y, Jendritzky G, Staiger H, Tinz B (2012) Comparison of UTCI to selected thermal indices. Int J Biometeorol 56:515-535. https:// doi.org/10.1007/s00484-011-0453-2

Borge R, Alexandrov V, del Vas JJ, Lumbreras J, Rodríguez E (2008) A comprehensive sensitivity analysis of the WRF model for air quality applications over the Iberian Peninsula. Atmos Environ 42:8560-8574. https://doi. org/10.1016/j.atmosenv.2008.08.032

Cheng F-Y, Hsu Y-C, Lin P-L, Lin T-H (2013) Investigation of the effects of different land use and land cover patterns on mesoscale meteorological simulations in the Taiwan area. J Appl Meteorol Climatol 52:570-587. https://doi.org/10.1175/jamc-d-12-0109.1

Cox R, Bauer BL, Smith T (1998) A mesoscale model intercomparison. Bull Am Meteorol Soc 79:265-284. https://doi. org/10.1175/1520-0477(1998)079<0265:ammi>2.0.co

Dudhia J (1989) Numerical study of convection observed during the winter monsoon experiment using a mesoscale two-dimensional model. J Atmos Sci 46(20):3077-3107. https://doi.org/10.1175/15200469(1989)046\%3C3077:NSOCOD\%3E2.0.CO;2

Emery C, Tai E, Yardwood G (2001) Enhanced meteorological modeling and performance evaluation for two Texas ozone episodes. Environment International Corporation. https://www.tceq.texas.gov/assets/public/ implementation/air/am/contracts/reports/mm/EnhancedMetModelingA ndPerformanceEvaluation.pdf. Accessed 13 Feb 2018

Gilliam RC, Pleim JE (2010) Performance assessment of new land surface and planetary boundary layer physics in the WRF-ARW. J Appl Meteorol Climatol 49:760-774. https://doi.org/10.1175/2009JAMC2126.1

Giovanni (2014) Monsoon Asia Integrated Regional Study. National aeronautics and space administration. http://gdata1.sci.gsfc.nasa.gov/daac-bin/ G3/gui.cgi?instance_id=mairs_8day. Accessed 17 July 2014

Gunwani P, Mohan M (2017) Sensitivity of WRF model estimates to various PBL parameterizations in different climatic zones over India. Atmos Res 194:43-65. https://doi.org/10.1016/j.atmosres.2017.04.026

Hartz DA, Golden JS, Sister C, Chuang W-C, Brazel AJ (2012) Climate and heatrelated emergencies in Chicago, Illinois (2003-2006). Int J Biometeorol 56:71-83. https://doi.org/10.1007/s00484-010-0398-x

Hernández-Ceballos MA, Adame JA, Bolívar JP, De la Morena BA (2013) A mesoscale simulation of coastal circulation in the Guadalquivir valley (southwestern Iberian Peninsula) using the WRF-ARW model. Atmos Res 124:1-20. https://doi.org/10.1016/j.atmosres.2012.12.002

Höppe P (1999) The physiological equivalent temperature—a universal index for the biometeorological assessment of the thermal environment. Int J Biometeorol 43:71-75. https://doi.org/10.1007/s004840050118

India Meteorological Department (IMD) (2017) Normal climate data. http:// www.imdpune.gov.in/hydrology/normal/norclim.html. Accessed 2 Nov 2017

Jiang Q, Tang C, Ma E, Yuan Y, Zhang W (2014) Variations of near surface energy balance caused by land cover changes in the semiarid grassland area of China. Adv Meteorol 2014:9. https://doi.org/10.1155/2014/89414

Kain JS (2004) The Kain-Fritsch convective parameterization: an update. J Appl Meteorol 43:170-181. https://doi.org/10.1175/15200450(2004)043<0170:TKCPAU>2.0.CO;2

Kumar R, Naja M, Pfister GG, Barth MC, Brasseur GP (2012) Simulations over south Asia using the weather research and forecasting model with chemistry (WRF-Chem): set-up and meteorological evaluation. Geosci Model Dev 5:321-343. https://doi.org/10.5194/gmd-5-321-2012

Kusaka H, Kimura F (2004) Coupling a single-layer urban canopy model with a simple atmospheric model: impact on urban heat island simulation for an idealized case. J Meteorol Soc Jpn Ser II 82:67-80. https://doi. org/10.2151/jmsj.82.67

Laaidi K, Zeghnoun A, Dousset B, Bretin P, Vandentorren S, Giraudet E, Beaudeau P (2012) The impact of heat islands on mortality in Paris during the August 2003 heat wave. Environ Health Perspect 120:254

Lin Y-L, Farley RD, Orville HD (1983) Bulk parameterization of the snow field in a cloud model. J Clim Appl Meteorol 22:1065-1092. https://doi. org/10.1175/1520-0450(1983)022<1065:BPOTSF>2.0.CO;2

Lo CP, Quattrochi DA (2003) Land-use and land-cover change, urban heat island phenomenon, and health implications. Photogramm Eng Remote Sens 69:1053-1063. https://doi.org/10.14358/PERS.69.9.1053

López-Espinoza ED, Zavala-Hidalgo J, Gómez-Ramos O (2012) Weather forecast sensitivity to changes in urban land covers using the WRF model for central Mexico. Atmósfera 25:127-154
Martin P, Baudouin Y, Gachon P (2014) An alternative method to characterize the surface urban heat island. Int J Biometeorol 59:849-861. https://doi. org/10.1007/s00484-014-0902-9

Mavrogianni A, Davies M, Batty M, Belcher SE, Bohnenstengel SI, Carruthers D, Chalabi Z, Croxford B, Demanuele C, Evans S, Giridharan R, Ye Z (2011) The comfort, energy and health implications of London's urban heat island. Build Serv Eng Res Technol. https://doi.org/10.1177/0143624410394530

Mlawer EJ, Taubman SJ, Brown PD, lacono MJ, Clough SA (1997) Radiative transfer for inhomogeneous atmospheres: RRTM, a validated correlated-k model for the longwave. J Geophys Res Atmos 102:16663-16682. https:// doi.org/10.1029/97JD00237

Mohan M, Bhati S (2011) Analysis of WRF model performance over subtropical region of Delhi, India. Adv Meteorol. https://doi.org/10.1155/2011/62123

Mohan M, Gupta M (2018) Sensitivity of PBL parameterizations on PM10 and ozone simulation using chemical transport model WRF-Chem over a subtropical urban airshed in India. Atmos Environ 185:53-63

Mohan M, Sati AP (2016) WRF model performance analysis for a suite of simulation design. Atmos Res 169:280-291. https://doi.org/10.1016/j.atmos res.2015.10.013

Mohan M, Pathan SK, Narendrareddy K, Kandya A, Pandey S (2011) Dynamics of urbanization and its impact on land-use/land-cover: a case study, of megacity Delhi. J Environ Prot 2:465-472. https://doi.org/10.4236/ jep.2011.24054

Mohan M, Kikegawa Y, Gurjar BR, Bhati S, Kandya A, Ogawa K (2012) Urban heat island assessment for a tropical urban airshed in India. Atmos Clim Sci 2:12. https://doi.org/10.4236/acs.2012.22014

Mohan M, Kikegawa Y, Gurjar BR, Bhati S, Kolli N (2013) Assessment of urban heat island effect for different land use-land cover from micrometeorological measurements and remote sensing data for megacity Delhi. Theor Appl Climatol 112:647-658. https://doi.org/10.1007/s00704-012-0758-z

Mohan M, Gupta A, Bhati S (2014) A modified approach to analyze thermal comfort classification. Atmos Clim Sci 4:13. https://doi.org/10.4236/ acs.2014.41002

Pleim JE (2006) A simple, efficient solution of flux-profile relationships in the atmospheric surface layer. J Appl Meteorol Climatol 45:341-347. https:// doi.org/10.1175/JAM2339.1

Pleim JE (2007) A combined local and nonlocal closure model for the atmospheric boundary layer. Part I: model description and testing. J Appl Meteorol Climatol 46:1383-1395. https://doi.org/10.1175/JAM2539.1

Ran L, Pleim J, Gilliam R (2010) Impact of high resolution land-use data in meteorology and air quality modeling systems. In: Steyn GD, Rao TS (eds) Air pollution modeling and its application, vol XX. Springer Netherlands, Dordrecht, pp 1-108

Ravindranath M, Ashrit R, Bohra AK (2010) Experiment on utilization of AWiFS LU/LC data in WRF mesoscale model. NCMRWF Report No. NMRF/ $\mathrm{RR} / 1 / 2010$

Rothfusz LP (1990) The heat index equation (or, more than you ever wanted to know about heat index). Tech. Attachment, SR/SSD 90-23, NWS S. Reg. Headquarters, Forth Worth, TX, 1990. https://www.weather.gov/media/ ffc/ta_htindx.PDF. Accessed 15 Oct 2017

Santamouris M, Cartalis C, Synnefa A, Kolokotsa D (2015) On the impact of urban heat island and global warming on the power demand and electricity consumption of buildings—a review. Energy Build 98:119-124. https://doi.org/10.1016/j.enbuild.2014.09.052

Sati AP, Mohan M (2017) The impact of urbanization during half a century on surface meteorology based on WRF model simulations over National Capital Region, India. Theor Appl Climatol. https://doi.org/10.1007/s0070 4-017-2275-6

Schlünzen KH, Sokhi RS (2008) Overview of tools and methods for meteorological and air pollution mesoscale model evaluation and user training. Joint Report of COST Action 728 and GURME, GAW Report No. 181, WMO/TD-No. 1457, WMO, Geneva

Shimadera H, Kondo A, Shrestha KL, Kaga A, Inoue Y (2011) Annual sulfur deposition through fog, wet and dry deposition in the Kinki Region of Japan. Atmos Environ 45:6299-6308. https://doi.org/10.1016/j.atmos env.2011.08.055

Silva HR, Phelan PE, Golden JS (2010) Modeling effects of urban heat island mitigation strategies on heat-related morbidity: a case study for Phoenix, Arizona, USA. Int J Biometeorol 54:13-22. https://doi.org/10.1007/s0048 4-009-0247-y 
Steadman RG (1979) The assessment of sultriness. Part I: a temperaturehumidity index based on human physiology and clothing science. J Appl Meteorol 18:861-873. https://doi.org/10.1175/15200450(1979)018<0861:taospi>2.0.co;2

Tan J, Zheng Y, Tang X, Guo C, Li L, Song G, Chen H (2009) The urban heat island and its impact on heat waves and human health in Shanghai. Int J Biometeorol 54:75-84. https://doi.org/10.1007/s00484-009-0256-x

Tewari M, Chen F, Wang W, Dudhia J, LeMone MA, Mitchell K, Ek M, Gayno G, Wegiel J, Cuenca RH (2004) Implementation and verification of the unified NOAH land surface model in the WRF model. In: 20th conference on weather analysis and forecasting/16th conference on numerical weather prediction, pp 11-15

Tomlinson CJ, Chapman L, Thornes JE, Baker CJ (2011) Including the urban heat island in spatial heat health risk assessment strategies: a case study for Birmingham, UK. Int J Health Geogr 10:1-14. https://doi. org/10.1186/1476-072x-10-42
UCAR (2014) User's guide for the advanced research WRF (ARW) modeling system. http://www2.mmm.ucar.edu/wrf/users/docs/user_guide_V3/ contents.html. Accessed 10 Sept 2014

USGS GLCC (2015) Global land cover characteristics data base version 2.0. https://ta.cr.usgs.gov/glcc/globdoc2_0. Accessed 13 Oct 2015

Vázquez SS, López ÁR, Souto JA, Casares JJ (2014) Validation of WRF model during $\mathrm{O}_{3}$ episodes in an Atlantic coastal region. In: Steyn GD, Builtjes JHP, Timmermans MAR (eds) Air pollution modeling and its application, vol XXII. Springer Netherlands, Dordrecht, pp 599-603

Willmott CJ (1981) On the validation of models. Phys Geogr 2:184-194. https:// doi.org/10.1080/02723646.1981.10642213

Yaglou CP, Minard D (1957) Control of heat casualties at military training centers. AMA Arch Ind Health 16:302-316

Yip FY et al (2008) The impact of excess heat events in Maricopa County, Arizona: 2000-2005. Int J Biometeorol 52:765-772. https://doi.org/10.1007/ s00484-008-0169-0

\section{Submit your manuscript to a SpringerOpen ${ }^{\circ}$ journal and benefit from:}

- Convenient online submission

- Rigorous peer review

- Open access: articles freely available online

- High visibility within the field

- Retaining the copyright to your article

Submit your next manuscript at $\boldsymbol{\Delta}$ springeropen.com 